\section{The effect of illustrations and simulations in \\ English course books in a Kazakhstani context on primary school students' English language achievement}

\author{
Bakhytgul A. Zhetpisbayeva ${ }^{a}$, Tatyana Y. Shelestova ${ }^{a,}{ }^{*}$, \\ Dinara A. Kazimova ${ }^{a}$
}

\author{
Received: 05 June 2017 \\ Revised: 21 August 2017 \\ Accepted: 24 August 2017 \\ ISSN: 1307-9298 \\ Copyright (c) IEJEE \\ www.iejee.com
}

DOI: 10.26822/iejee.2017131946

\begin{abstract}
Course books are the most important teaching and learning materials. In English language course books for primary school students, simulation and illustrations should occupy a prominent place in teaching and learning processes. This qualitative study aims to investigate the effect of illustrations and simulation in English Course Books in a Kazakhstani context on primary school students' English language achievement by means of self-developed teaching aids ("Dictionary in pictures for primary school", "Grammar in pictures for primary school", "Alphabet and spelling in pictures for primary school"). The literature review showed that simulation and illustrations play a role in primary school students' perceptions of classroom activities (i.e., motivation, interest, challenge and joy). It was also hypothesized that simulation and illustrations affect English language achievement. To do so, the study utilized an experimental design consisting of 116 participants (58 students in the control group and 58 students in the experimental group). The results demonstrated the positive role of simulation and illustrations in students' language achievement. An interview was also held with a number of English language teachers to investigate their attitude towards self- developed teaching aids.
\end{abstract}

Keywords: Material development for primary school, Simulation, Illustrations, Classroom activities, Language Achievement

\section{Introduction}

The socio-economic development of the modern Kazakhstan is taking place within the framework of the five institutional reforms put forward by the President of the country N.A. Nazarbayev. The strategy of their implementation is clearly and distinctly stated in the adopted program document "One hundred steps of N. Nazarbayev". This plan of reforms has been called by the Head of the State the "Plan of the Nation", the implementation of which should become the "number one" task for the next 10-15 years.

In order to implement the indicated reforms, the following steps should be taken in the system of education, in particular, step 79 provides for the gradual transition to the English language teaching in the education system - in the senior school classes and the higher school.

In these conditions, the problem of teaching foreign languages (hereinafter - FL) in the primary school is especially actual; its strategy should be built in accordance with the new priorities of the school in the 21stcentury, the school as a source of development of abilities and creative activity of learners capable of independent problem solving in the form of communication. The educational subject "Foreign language" has great potentialities of the impact on the learner's personality, since all the spheres of human communication are affected and all the spheres of life are covered. Moreover, the study of this subject should be carried out in accordance with the new State obligatory standard of the primary education, the typical curriculum and the typical English language educational programs. The task is complicated by the fact that the State program for the development of education and science of the Republic of Kazakhstan for 2015-2019 provides for a phased transition to the trilingual education.

The analysis of the current situation and the survey of teachers, who teach English in the primary school, allowed us to clarify that learners starting to study FL encounter a large number of difficulties affecting motivation and subject interest and, accordingly, the effectiveness of mastering $\mathrm{FL}$. The reasons for the difficulties are rooted in the organization of the first year of FL studying: insufficient attention to the psychophysiological capabilities of the junior school age, the lack of didactic materials offered in the English language textbooks for the primary school, which correspond to 
communicative and cognitive interests and needs of learners and their linguistic and speech experience in the native (Russian or Kazakh) and English languages (Zhetpisbayeva \&Shelestova, 2016).

The analysis of strategic documents in the field of the primary education has made it possible to distinguish between the current State obligatory standards of education, typical curricula and typical educational programs for the transition period and similar documents of 2015, which are as follows:

1. cross-cutting topics are defined for the primary school in the new typical educational programs (2016);

2. for the primary school typical educational programs in the three target languages (Kazakh, Russian and English) set the levels specified in the same way as in the CEFR (Common European Framework of Reference). At the same time, when the level of language proficiency is distributed, English "step" one step behind the Kazakh and Russian languages, since the latter are studied in the natural linguistic environment. Therefore, for the English language in the primary school, an additional level "Work towards A1" is given.

3. level teaching also emphasizes the development of skills in four types of speech activity: listening (comprehension with understanding of oral speech), speaking, reading and writing. At the same time for the early teaching of English the following is conceptually significant: if for the second languages (Kazakh and Russian) all four types of speech activity are allowed, for the third language (English) in the first grade the emphasis is made on two types of speech activity: listening and speaking.

The State obligatory standard of the primary education of 2015 directs teachers to organize the educational process in a completely new format, which raises many questions among teachers about the specifics of this activity. How to organize the process of teaching a foreign language in accordance with the new requirements? What is the principle of integration and the complex thematic approach? How in the process of "living through" the topic to cover the program objectives of all the educational areas and not to miss something? The modern educational process in the primary school should be built on activities that are important for the development of learners: game, communicative, cognitive-research, productive, labor and other.

It should also be noted that the concept of methods, forms of organization of activities at the initial stage of teaching a foreign language has been significantly changed. Today, the main form and the leading type of activity is a game, and the way of organization of types of speech activity is joint (partner) activity with learners.

The peculiarity of teaching English in the 1st grade, according to the State Educational Program for primary education (2015) is the combination of the following characteristics:
1. two main types of speech activity - listening and speaking - are the objects of teaching;

2. simultaneity in the development of the types of speech activity (listening and speaking) is provided; it means that each type of speech develops from the very beginning of teaching and that the development of one type contributes to the development of others (reading and writing), facilitates their mastery;

3. teaching is organized within the framework of a certain sequence-temporal correlation of the types of speech activity (first, listening and speaking, then reading and writing);

4. teaching types of speech activity is organized on the basis of the common linguistic material, which should serve as the basis for the development of speech activity;

5. teaching is conducted on the basis of exercises.

Undoubtedly, the alignment of activities in accordance with the new requirements identified in the State Educational Program for primary education of 2015 for the majority of teachers is the new task that requires certain knowledge. The new policy has allowed considerable local autonomy in textbooks development. In 2011, the Ministry of Education and Science (MES) of the Republic of Kazakhstan set up a curriculum and instructional kits (CIK) evaluation committee responsible for assessing locally developed textbooks and granting publication permissions. Subsequently, several agencies and institutions were commissioned to develop new English language textbooks for use in primary schools in Kazakhstan (Zhetpisbayeva \& Shelestova, 2016).To implement the goal of the early teaching FL registered in the State Educational Program for primary education of 2015 in order to help teachers, the curriculum and instructional kits (CIK) has been developed by the authors of this article.

The developed CIK consists of the author's teaching aids ("Dictionary in pictures for primary school", "Grammar in pictures for primary school", "Alphabet and spelling in pictures for primary school") for the early English language teaching to the first grade students, which can be used as additional training tools together with the main Course Books recommended by the Ministry of Education and Science of the Republic of Kazakhstan for the implementation of the state standard in the educational process. These publications have been reviewed in the Scientific and Methodological Council of the university, and received an approving opinion from the regional department of education.

The reference point for writing and compiling teaching aids that regulate the content of the early Foreign language teaching in the primary school was provided by the State obligatory standard of the primary education of 2015, the typical educational program on the subject "English language", the "English language" educational program (in the framework of updating the content of the secondary education, 2016). 


\section{Literature Review}

Course materials "play a key role in language education" (Basal, 2013, p.11) in teaching and learning processes. Without illustrations, "presenting learning materials merely through textual information may not lead to efficient learning demanded by the excessive amount of information" (Kuzu, Akbulut\&Şahin, 2007, p.8). Moreover, "even when the text is comprehensible without a picture, pictures can support the comprehension process in many ways" (Molitor, Ballstaedt\& Mandl, 1989, p.16). Çakır (2015) also claims that "in order to create a meaningful learning atmosphere and to offer a comprehensible input, word and pictures need to be presented simultaneously" (p.71). In a study conducted by Teele (1995) with the use of the inventory developed by the researcher based on the Multiple Intelligence Theory of Howard Gardner, all of the 26 participants of the study were visual and kinesthetic learners, showing the importance of illustrations in teaching and learning processes. When benefitted from visualization, our minds comprehend the gist fast (Laitinen, 2014). In this context, illustrations can be considered important educational and communicative tools and their frequency of occurrence and to what function these occurrences serve can give practitioners useful insight into how they best identify, classify, and modify them for their instructional purposes. To this end, this study aims to investigate the frequency with which the illustrations occur in English course books and the functions they serve (Basal, Celen, Kaya \&Boğaz, 2016).

Students' encounters with language in their daily lives are laden with audial and visual input (Domin, 2007). The availability of such input has facilitative effects on communication both for non-native and native speakers of a given language by enabling the speakers to fully understand the context in which the communication occurs and interpret the message accordingly. When used in course books, illustrations may thus serve a similar purpose, and the benefits of such an inclusion can be twofold: guidance for students and use of authentic sources. Hewings's (1991) definition of the term 'illustration' in a teaching material covers any input except for text such as "drawings, cartoons, photographs, flow charts, pie charts, graphs, and tables" (p. 237).

Most of the studies on simulation have been conducted to assess the effectiveness of such a teaching technique and find its benefits related to some skills. Such studies prove that using simulation as a kind of language assessment model promotes cross-cultural communication (Crookall, Coote, Dumas, \& Le Gat, 1987; Crookall\& Oxford, 1990) and instrumental motivation by making the coursework more engaging (Jones, 1986, p. 10). Other studies support the fact that simulation lowers affective barriers to acquisition by reducing the fear of making mistakes (Nemitcheva, 1995) and presents real time scenarios and instantaneous feedback (Jones, 1986). It also benefits language learners to use language in highly specific contexts (Brown, Collins, \& Duguid, 1989) and provides a meaningful way of learning a language (Sam, 1990). Moreover, simulation promotes metacognitive strategy use (Bullard, 1990), improves students' desires to learn (Davis, 1996), and makes learning and teaching process a rewarding experience for both students and teachers (Tompkins, 1998). Similarly, it guides learners progressively towards the final goal of learning as well as assessment purposes and lets the teacher to play the role of a facilitator who share students' knowledge and opinions among themselves (Albert, 1999). Besides such benefits it helps learners to set realistic and communicative goals, assesses the features of a language use situation, and helps students to plan responses and have control on the execution of such plans (Ranalli, 2008). It can also provide realistic sociocultural contexts for language learning by bridging the gap between students and the foreign culture (Schwienhorst, 2002) and motivate shy learners to take part in discussions more actively (Freiermuth, 2002). In a similar vein, simulation gives learners the opportunity to solve problems without the authoritative persuasion of the teacher by providing a learner-centered context (Freiermuth, 2002, p. 187) and provides the content for language learning via meaningful and cohesive contexts (Purushotma, 2005, p. 84). It is also capable of enhancing learners' grammar and vocabulary knowledge (Miller \&Hegelheimer, 2006), as well as causing them to reflect more positive attitudes towards collaboration and providing positive reaction to the modifications among the users (Ranalli, 2008). Simulation has been also found to be significant in promoting vocabulary skills (Ranalli, 2008) and students' second language vocabulary recall (deHaan, Reed, \&Kuwada, 2010). Finally, it makes the teachers more flexible to take students' individual differences into account (Wang, 2010), motivates students by providing challenging opportunities for authentic discussions (deHaan, 2011), improve students' oral communicative skills (Javid, 2013), and promotes English vocabulary and pronunciation learning of ESP students (Meihami, Meihami, \&Varmaghani, 2013).

\section{Method}

To test the effectiveness of the developed teaching aids, experimental work was organized. Author's publications were introduced into the educational process and were used as additional teaching aids during the academic year in English classes in the first grades. The experiment was carried out in two schools, one of which formed control groups (Communal public institution "Educational complex "school-kindergarten" No.77", Karaganda), the other one - experimental groups (Communal public institution "GymnasiumNo.3", Karaganda).

The peculiarity of the experimental base of our study is that the gymnasium No. 3 of the city of Karaganda was at that time a pilot school for the approbation of the new State obligatory standard of the primary education of 2015.

When developing the CIK in English, we took into account the external and internal structures of didactic means (in particular, its publishing and printing features, visualization of speech and grammatical material). If not to take into account the design of this component during the creation of the textbook / CIK, then the danger is inevitable that the author of the Course Books will concentrate all attention on the selection of linguistic and speech (communicative) material, on the frequency of vocabulary and grammatical phenomena, etc., not paying 
attention to the factors that affect the motivationallyneedful and emotional sphere of the learner's activity (N.D. Galskova).

\section{Instruments}

The author's teaching materials and aids ("Dictionary in pictures for primary school", "Grammar in pictures for primary school", "Alphabet and spelling in pictures for primary school"). Author's teaching aids and teaching material are publications that contain lexical and grammatical material in pictures (according to the typical educational program on the subject "English language" for grades 1-4). The system of exercises based on activities (simulations) with the visual presentation (pictures, diagrams, etc.) helps children to learn the speech material. The pictures are used in the lesson as a support for the solution of the speech-thinking tasks offered by the teacher, while performing exercises, as well as for reflecting the success of the learners' activity in learning English.

\section{Discussion}

Teaching the sound side of the foreign language speech to children with the help of the author's teaching aid "Alphabet and spelling in pictures for primary school" is associated with the development of the foreign speech hearing and the formation of the ability of phonological awareness of the foreign speech without the reliance on the printed text.

We distinguish the following objects of the formation and development: (1) skills of the auditory perception and pronunciation of sounds, words and patterns of communication that contain them; (2) skills of meaning distinguishing / distinguishing between long and short vowel sounds, dental and interdental consonants, etc.; (3) phonological skills "responsible" for the phonological awareness of the foreign language speech.

In accordance with these three objects, we distinguish three groups of exercises.

The first group contains exercises on the perception and pronunciation of sounds and words containing them. Here is a fragment of the onomatopoeic game-exercise using the method of the conscious imitation, when children follow the rule and learn to control their articulation organs, when the sound $[r]$ is pronounced.

Teacher: "Guys! Have you heard how a dog growls? Will you also growl, but not loud, in order not to scare the other learners? And Tom's dog does not growl like that - its tongue is located on the ridge behind the upper teeth. Touch the ridge with your tongue and say [r-r-rr]. Aliya! L1: [r-r-r-r]; Samat! L2: [r-r-r-r], etc.

The second group is:

1. exercises for differentiating sounds (long and short vowels, interdental, sibilant consonant sounds), words and patterns of communication that contain them by ear;

2. exercises for sound / phonemic analysis of the word - by ear.
Here are some examples.

Teacher: "Tom's watch is fast [tik-tik-tik], then slow: [ti:k - ti:k-ti:k]. Guys, how is Tom's watch fast?" Learners: [tik - tik - tik]. "And how is it slow?" Learners: [ti:k - ti:k -ti:k].Then learners are asked to clap their hands once, if they hear a word with a short sound [i] and many times if they hear a word with a long sound [i:].Teacher: “Listen carefully: [milk- mi:t-ti: - it - i:t- ri:d]", etc.

The third group is:

a. to select and correctly pronounce the sound in the beginning of the word. For example: the teacher pronounces the word "window" - the learner pronounces the first sound of the word [w];

b. to hear and reproduce ("slam") the rhythmic pattern of the phrase;

c. to combine sounds in one word. For example: the teacher pronounces individual sounds [p - e - n], the learner "collects" them into one word and pronounces - [pen];

d. to recognize the rhyme - the same sounding words. For example: the teacher pronounces four words "cat-fox-duck-hat", and the learners should name two that rhyme with each other (cat-hat).

The development of the lexical level of the foreign language ability through the use in the English classes of the author's teaching aid "Dictionary in pictures for primary school" is connected with teaching a word as a tool of speech activity and is associated with the development of phonetic and grammatical levels of this ability.

The main task in introducing new words is to create motivation for children to learn these words and provide orientation in their use. Words, according to the data of psycholinguistic experiments, undergo a process of generalization and are stored in memory in the form of groups related to the semantic feature; therefore it seems to be methodically expedient to acquaint learners with a group of words $(5+/-2)$ related to one or another sphere of reality. It is necessary to enable children to interact and communicate, starting with the first lessons.

Teaching vocabulary begins with the development of the auditory perception as the most important cognitive function - learners perceive words by ear with the support of the visual presentation. To form the motive for acquainting them with a particular group of words, a problem-oriented story method is used, the main task of which is to help children realize the necessity of learning these words, seeing the meaning in their learning. It is possible if the story is very short and its plot is included in the context of the game activity - only in this case there will be the awareness of the importance of the word (group of words) for the transmission of one or another communicative intention. Here is an example of such a story, in order to familiarize learners with new words food (butter, bread, porridge, meat, tea, juice). The teacher says: "Guys, we need to prepare for a long 
journey and buy food. Let's see what products are there in the English store: butter, bread, etc.

This technique helps learners to see the point to learn new words and learn how to use them in speech -they should know these words to buy food in the English store and prepare for a trip.

Before children begin to create phrases with new words, it is necessary that words undergo the process of interiorization, in accordance with patterns, which is provided by a system of lexical exercises aimed at the gradual formation of children's ability to independently use words in the composition of various utterances.

In accordance with this, we distinguish the following system of exercises, which are aimed at:

1. the perception of new words by ear and their recognition on the basis of pictures / objects;

2. the perception of words by ear and their recognition on the basis of the performance of actions with objects;

3. the use of words on the basis of pictures / objects;

4. the independent use of a word in the phrase with a choice;

5. the independent use of a word in the phrase without a choice.

For the development of the dialogical speech, we use exercises aimed at:

1. the independent choice of the necessary speech pattern for the answer, question or any other remark in a specially created game situation;

2. the development of skills to ask questions of various kinds and use other remarks-stimuli;

3. the development of skills to expand a response remark in a micro monologue.

For the development of the monologic speech we use the following types of exercises:

1. to stimulate short statements (one sentence long) in connection with the proposed game situation;

2. to clarify or substantiate what has been said that suggests the extension of statements in two or three sentences;

3. to independently construct a coherent text (4 - 5 sentences long):

1. to prove your own statement;

2. to refute the statements of your interlocutor;

3. to collectively compile a coherent statement-text;

4. to develop speech production.

The formation of the grammatical ability is provided by the developed system of exercises based on the visual presentation and given in the author's teaching aid "Grammar in pictures for primary school", which is aimed at the fact that the mastery of grammar by learners is interconnected with mastering the word and the phoneme as instruments of the foreign speech activity and is included in the process of speaking in another language.

For example:

1. reproductive substitution exercises, which strengthen the children's awareness of the functional aspect of the grammatical phenomenon / speech pattern, help memorize the formal side and develop the ability to use forms on the basis of analogy. Let us give an example of such a game speech-thinking problem using the verb "can" and its solution by the teacher and learners: "A forest fairy will unspell our animals (motive) if we tell what they can do (goal). "First, I will tell", - the teacher gives a sample solution to the problem: My frog can jump. Learner 1: My cat can run. Learner 2: My parrot can fly", etc.

The peculiarity of this and the following types of exercises is that the speech pattern and the speech-thinking task are common to all, but the communicative intention is expressed by each learner individually by telling (rather than imitating the teacher) about something. In this case, children are encouraged not to repeat the speech pattern or to confirm that his/her dog also can run. They are set the task, for example, to unspell their animals, and to do this (and this is the motive, for which they will act), the learners need to tell what their animals can do (this is the goal of this speech action).Both the motive and the goal, presented to the pupils in an understandable way, require the use of the necessary pattern of speech.

2. exercises for expanding the speech pattern and varying its content by using adjectives, adverbs, numerals;

3. transformational exercises aimed at the further development of the "function-form" association, at the formation of the skill of choosing a speech pattern in accordance with the speech plan and in accordance with the situation of communication and at the formation of the internal image of the speech pattern;

4. combination exercises, completing the formation of the grammatical ability.

Speech-thinking problems should be formulated in such a way as to stimulate learners to construct a statement first from two, and then from three speech patterns. Let us give an example. Teacher: "Our time machine will be on a magical island, if we see animals in a window and tell what color they are". Children are offered pictures of different animals. The teacher speaks first: "I see a bear. The bear is brown". Learner1: I see a crocodile. The crocodile is green. Learner2: I see a dog. The dog is black, etc.

Grammar exercises are the active means of the cognitive and communicative development of learners in mastering foreign grammar.

The peculiarity is that from the very beginning learners are provided with the opportunity for self-expression within the framework of the solution of the general speech-thinking problem; all exercises have the character of communication, which creates conditions for the involuntary memorization (at the unconscious level) and 
the sensual mastery of the grammatical form, because children perceive and generate meanings.

Supports in the form of diagrams, models (which at this stage are already feasible to children), tables, pictures and speech patterns with the elements highlighted with different colors serve to better awareness by the learners of the essence of the grammatical phenomenon and "work" to create a more complete and generalized framework.

\section{Procedure}

All three of the above teaching aids were used in the educational process as an additional teaching material in English classes in the first grades.

The experiment was designed for 1 academic year (20152016) and was conducted in the conditions of the natural educational process in English in the Communal public institution (CPI) "Gymnasium No.3" and the Communal public institution "Educational complex "schoolkindergarten" No.77" of the city of Karaganda. The number of participants of the educational process, who took part in the experimental teaching, is reflected in Table 1.

Table 1. Contingent of participants in the experiment

\begin{tabular}{lllll}
\hline No. & Grade/class set & School & Number of learners & Number of teachers \\
\hline 1. & 1 grade (2) & CPI “Gymnasium No.3” & 58 & 5 \\
2. & 1 grade (2) & $\begin{array}{l}\text { CPI “Educational complex “school- } \\
\text { kindergarten” No.77” }\end{array}$ & 58 & 5 \\
Total & 4 class sets & 2 schools & 116 & 10 \\
\hline
\end{tabular}

The purpose of the experiment was as follows:

- $\quad$ on the basis of the developed criteria to assess the author's teaching aids on English for the primary school by the expert evaluation method and to test their effectiveness in teaching English to the first grade pupils;

- to reveal the dynamics of the formation of the foreign speech activity of the first grade pupils, who used author's teaching aids in the process of teaching English;

- $\quad$ to process the obtained diagnostic results using statistical methods of the descriptive analysis.

The overall direction of the experiment was carried out within the framework of the scientific-research project "Scientific and methodological support of the early teaching foreign languages" funded by the Ministry of Education and Science of the Republic of Kazakhstan and was implemented by the scientific-research laboratory on the problems of language education of E.A. Buketov Karaganda State University under the guidance of the doctor of pedagogical sciences, professor Zhetpisbayeva B.A. Observation of the course and results of the experiment was carried out in the close contact with the teachers-methodologists in the English language of the Communal public institution "Gymnasium No.3" and the Communal public institution "Educational complex "school-kindergarten" No.77".

The main indicators, on which the conclusions were made about the effectiveness of the use of the CIK in English for the primary school in teaching the first grade pupils, were obtained in the course of analyzing the observations of the educational process, the questionnaire survey of teachers and the results of control tests.

To assess the effectiveness of the CIK, the expert evaluation method was applied, as it was stated above. Experts were teachers, who taught junior schoolchildren through this CIK. The experts were asked to answer 10 questions included in the scale of criterial evaluation
(Table 2). For each of the questions that had the nature of the criteria, one of the four answers could be given; each variant was given a weight in scores: Yes - 3; Rather, yes, than no - 2; Rather no, than yes - 1; No - 0 . Thus, the maximum possible score for each question was 30 . This number was made up of the maximum score for each question (3) multiplied by the number of respondents from the methodological associations of schools (10).

In the course of the experiment, the teacherexperimenter needed to monitor the progress and results of children's learning the types of the foreign language speech activities through the author's publications, as well as to evaluate the educational and methodical complex on the English language in the following areas:

educational material for the lesson, a series of lessons (sufficient, not sufficient, excessive);

- feasibility of the educational and methodical complex;

- the most successful tasks, games, illustrative material;

- typical mistakes of learners, the reasons for their occurrence;

- special difficulties that the teacher encountered during the experiment;

difficulties that the learners encountered;

- proposals for the correction, exclusion or addition of material, for the replacement of wording of tasks, games, etc. 
Table 2. CIK assessment criteria

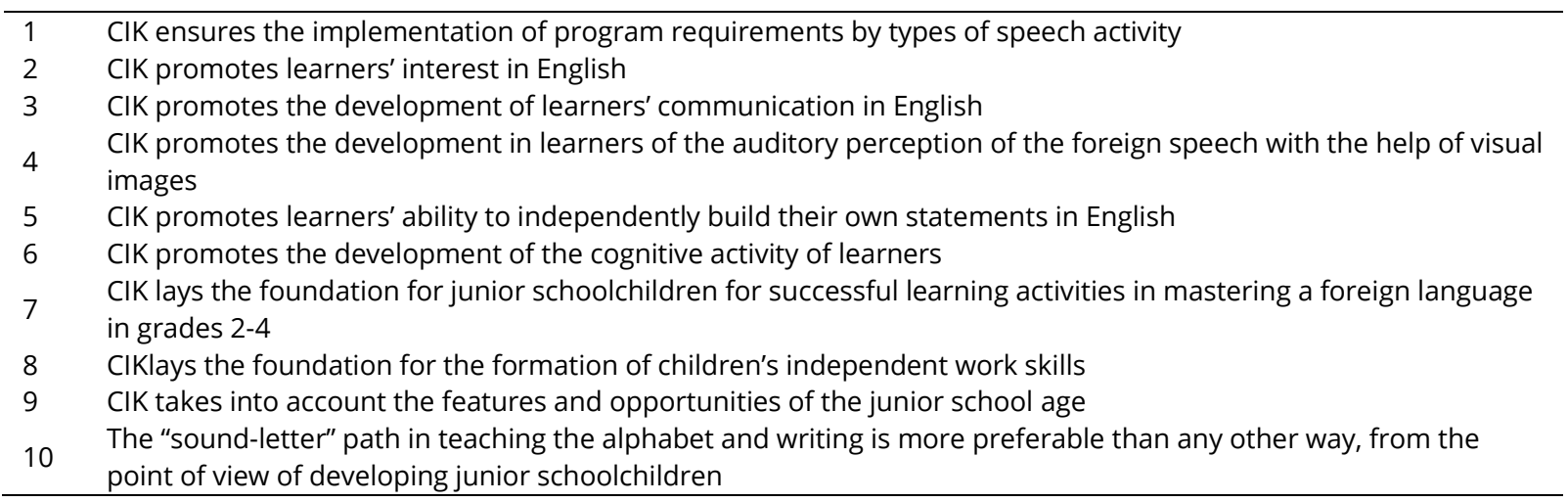

\section{Results}

The analysis of the questionnaire data of teachers and methodologists indicated a positive assessment of the CIK in English for the primary school and its use in the educational process; according to respondents, it ensures the implementation of program requirements for the types of speech activity and contributes to the formation of the main types of speech activity in the 1st grade (listening and speaking).

All teachers have noted that CIK materials contribute to the development of children's interest in learning FL and their cognitive activity. Here are the extracts from the teachers' reports, confirming the conclusions drawn above:

"Most importantly, if at first the learners did not understand and did not realize the new language as the significant phenomenon, then in 4 months they became a group of creative and forming people, and the language was perceived by them as something necessary and useful. These educational materials form and organize learners in creatively working people" (from the report of the teacher of English of the Communal public institution "Gymnasium No.3").

"Most of the tasks are constructed so that the learner is faced with the need for a mental effort" (from the report of the teacher of English of the Communal public institution "Gymnasium No.3").

"The possibilities of illustrative forms as a pedagogical means for the presentation of educational material that take into account the connection with other components of the CIK are fully used" (from the report of the teacher of English of the Communal public institution "Gymnasium No.3").

"The tasks are constructed in such a way that children should exert mental efforts to comprehend the situation, to guess the meaning of the word, to construct their utterance in the same way as the proposed sample, which contributes to the solution of the general task of the primary school to gradually accustom the learners to overcome difficulties in intellectual work" (from the report of the teacher of English of the Communal public institution "Educational complex "school-kindergarten" No.77").

"Children learn to communicate among themselves, learn to be active, learn what is lacking in the higher stages of teaching. It is through the game that we reach the set educational goal - learners begin to speak English" (from the report of the teacher of English of the Communal public institution "Educational complex "schoolkindergarten" No.77").

"The educational material provides the learners with the opportunity to express themselves in the process of performing a task, allows developing the abilities of each learner" (from the report of the teacher of English of the Communal public institution "Educational complex "school-kindergarten" No.77").

At the same time, a number of comments and offers have been made, among which the following most significant can be singled out: the insufficient use of tasks for pair and group work; the necessity to increase a number of tasks that require self-and mutual control.

The analysis of teachers' comments in relation to the weight of each answer allowed the submission of the rating of teaching aids. According to the results obtained, the overall rating is $270(91 \%)$ out of $300(100 \%)$ possible, which indicates a rather high appreciation of the author's publications.

When assessing, it has been noted that one of the strengths of the EMC is its visual presentation as a way of presenting educational information that takes into account the age characteristics of learners. Experts in the evaluation of the EMC made interesting comments confirming in our study the theoretical propositions and explicating the developing and educational effect of the developed method of the early education.

To check the effectiveness of the developed CIK for the early English teaching, control tests have been made for the types of the foreign-language speech activity in the 1 st grade (listening and speaking) in order to establish the level of the English language proficiency for the first grade pupils at the end of the academic year and compare the data in the control group (CG) (58 learners) and experimental (59 learners) group (EG). 
Assessment of knowledge of the first grade pupils by the types of speech activity (listening and speaking) took place in several stages.

Stage 1 is ascertaining, including the entrance control in the beginning of learning English in the 1st grade (quarter 1 ) in control and experimental groups.

Stage 2 is final, including the final control at the completion of learning English in the 1st grade in control and experimental groups.

Assessment included data collection and preparation of the assessment report. Report data are the input data for the monitoring process; they included:

- contingent of learners;

- criteria for assessing listening and speaking, according to the requirements of the State obligatory standard of the primary education of 2015 and CEFR;

- analysis of the data collected, interpretation of results;
- conclusions and recommendations obtained on the basis of the assessment of the formation of the types of speech activity in English (listening and speaking) after completing the English language learning in the 1st grade using the methods of testing, data collection, observation.

The ascertaining experiment was carried out in the 1st grade at the end of the 1st quarter according to the results of listening and speaking as the types of speech activity. On the basis of the results of teaching in the $1^{\text {st }}$ quarter, control tests on the types of speech activity were made in the classes of experimental schools. Control works were developed in accordance with the requirements of the English language program and included not only tasks, but also methodological guidelines for their conduct and calculation of results.

The objective analysis of the results of the ascertaining experiment has shown that, in general, the level of the foreign language skills in the control and experimental groups is the same, which is reflected in Table 3.

Table 3. The results of the ascertaining experiment by the types of speech activity (1st quarter, 2015-2016 academic year)

\begin{tabular}{lllllll}
\hline & \multicolumn{2}{l}{$\begin{array}{l}\text { Speaking } \\
\text { Dialogical speech }\end{array}$} & Monologic speech & \multicolumn{2}{l}{ Listening } \\
\cline { 2 - 7 } Levels & CG & EG & CG & EG & CG & EG \\
& $(58$ learners) & (58 learners) & (58 learners) & (58 learners) & $\begin{array}{l}\text { (58 } \\
\text { learners) }\end{array}$ & learners) \\
\hline high & $3 \%$ & $2 \%$ & $3 \%$ & $3 \%$ & $2 \%$ & $2 \%$ \\
medium & $25 \%$ & $31 \%$ & $23 \%$ & $29 \%$ & $16 \%$ & $18 \%$ \\
low & $72 \%$ & $66 \%$ & $74 \%$ & $68 \%$ & $82 \%$ & $80 \%$ \\
\hline
\end{tabular}

The materials reflected in the table above show that in the beginning of the experimental work in mastering by the learners of the control and experimental groups the types of speech activity (speaking and listening), no significant differences have been found.

At the final stage of the experiment, the effectiveness of teaching English to the first grade pupils was tested.

The indicator of the foreign speaking ability in the $1^{\text {st }}$ grade is the ability of learners in the types of speech activity: listening and speaking, the level of the formation of which is set by the typical educational program on the subject "English language", the State obligatory standard of the primary education of 2015 and CEFR (A1), which were tested with the help of the control tasks developed by us.

Here is an example of the task to check a learner's ability to understand an authentic text by ear with the extraction of general and detailed information.

The control work was carried out as follows. The teacher handed out to each learner a sheet with the tasks "Listening Paper", in which they marked the correct answers after listening to the text. Estimated time for performing the task was 15 minutes. After completing the task, the learners listened to the text a second time and checked the correctness of the work done.
Here is the task before listening to the text: "Listen to the story of how the girl Polly dressed up in the store. Complete the tasks individually after listening to the text".

\section{Example: he text for listening}

Polly is a little girl. Polly wants to have a new dress. "Mum," she says, "Let's go to the shop. I want to have a new dress."

"Let's go!" says Polly's mother. So they go to the shop.

"What dress do you want, Polly?" asks Polly's mother in the shop.

"I want a red dress," says Polly.

"All right, Polly, take it please," her mother says. Polly puts the dress on.

"And this dress I want too, Mummy! This yellow dress with red flowers!"

"All right, take it please," says Polly's mother. Polly puts one more dress on.

"Mummy, and that green dress is beautiful too! I want it very much! May I also put it on?"

"Yes, Polly, you may," says Polly's mother, "but now you are not a little girl, you are a little cabbage!" 
After listening to the text, each learner received a sheet with the tasks "Listening Paper". Teacher read out tasks to learners and variants for answers, and learners chose the right answer using the visual prompts. The maximum number of scores for all the tasks was 10.

For example:

Task 1. Complete the sentence by choosing the correct answer: a) or b).

1. Polly is

2. Polly wants to have

3. Polly wants a) a little girl

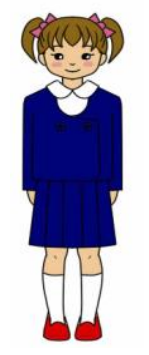

a) a new doll

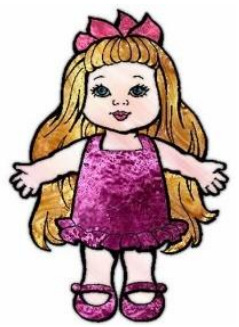

a) a red dress

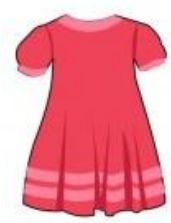

b) a teacher

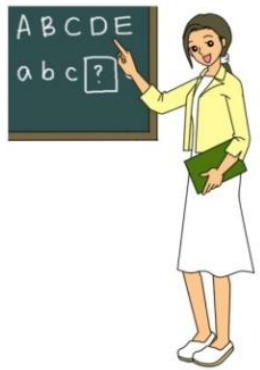

b) a new dress

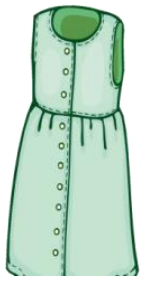

b) blue trousers

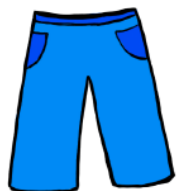

Task 2. Circle the colors of the dresses Polly likes.

red

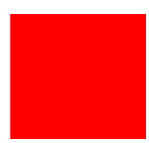

green

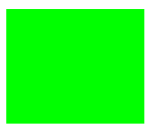

blue

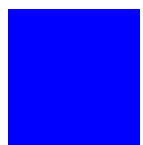

yellow

brown

pink
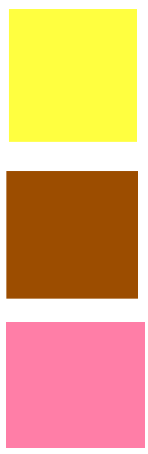
Guided by the scale of assessing the development of learners' ability to listen in the foreign language, the results for each learner were recorded separately.
Figure 1 presents a diagram of the indicators of the level of the formation in junior schoolchildren of listening skills.

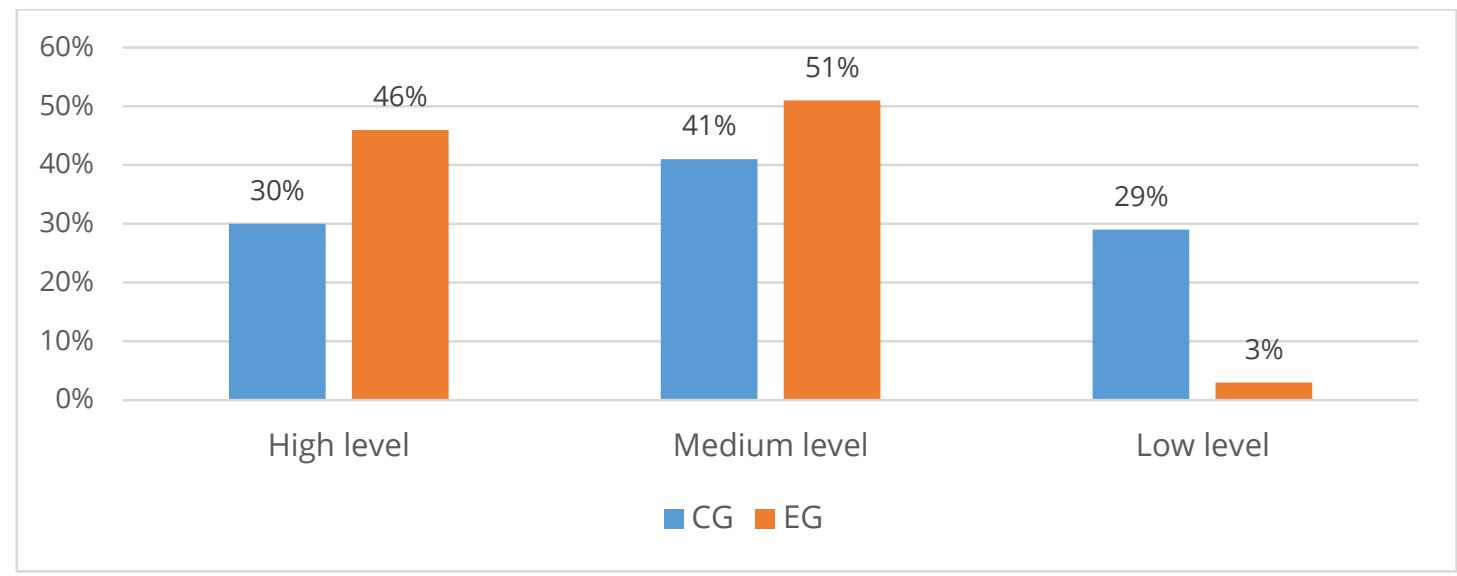

Figure 1. Indicators of the formation of listening skills in junior schoolchildren

According to the data obtained, the share of EG learners with high results of the formation of the ability to listen was 46\%; with medium results - 51\%; with low results $3 \%$.

The formation of the ability to listen in CG is a little bit lower. The high level was demonstrated by $30 \%$ of learners, the medium and low levels - by $41 \%$ and $29 \%$ respectively. This indicates an improvement in the quality of the formation of the foreign language listening among all learners.

The main purpose of the control tasks for speaking is to check the degree of the learners' formation of the ability to build independent statement in the dialogical and monologic form in accordance with the program requirements. In the first task, the object of the check was the ability of learners to build a monologic utterance, using one of the basic communicative types of speech: description, message, and story.

In the second task, the object of control was the ability of learners to construct dialogical utterances, using dialogue-inquiry, dialogue-exchange of opinions, and dialogue-incentive for action. The tasks were offered in the Russian and English languages. The teacher formulated the task in Russian or English at his/her own discretion, depending on the level of the group's preparation.

The conditions for carrying out this type of control were as follows.

Control was conducted in the game form. The teacher described the game situation, formulated the task, offered the learners the necessary means of the visual presentation and played the role of fairy-tale characters, who participated in the control situation. The results of the check were entered in the table.
In contrast to the listening control, which had a frontal form of check, control of speaking was carried out individually with each learner. The dialogical speech control was conducted in pairs. The control was carried out in the form of the game.

Let's give an example of tasks for checking the monologic (task 1) and dialogical (task 2) speech. In the first task, the learner's ability to construct a monologic utterance was tested. In the second task it was the ability of learners to conduct a dialogue-inquiry.

Task 1forthelearner: Winnie the Pooh (or any other character) came to visit us. He wants to get acquainted with you. Tell him about yourself, your family, about what you can do and what you love.

Task for the learner: Today Alina is a seller in a toy store. Alina politely asks children what they want to buy, and offers them various toys.

Monitoring was carried out in the form of the game "In a toy (stationery, furniture, clothing) store". All the learners took turns in the role of the seller.

Means of visual presentation: the component of the author's EMC ("Dictionary in pictures for primary school"), pictures of toys, stationery, clothing, furniture. Pictures were laid out on the desk, as in the shop window, in front of the learners.

Guided by the scale of assessing the development of learners' ability to speak in the foreign language, the results for each learner were recorded separately.

Figure 2, presented below, shows the results of the analysis of the formation of skills of the foreign language speaking in the first grade pupils. 


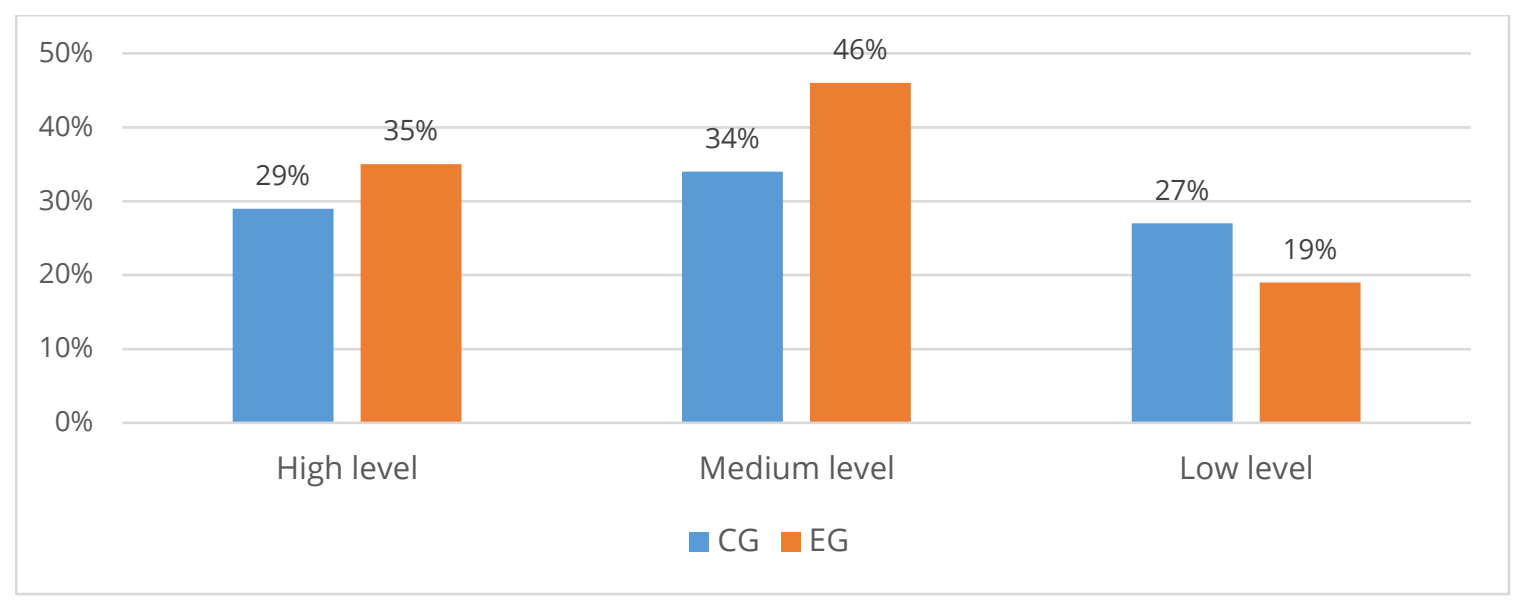

Figure 2. Indicators of the formation of foreign language speaking skills in junior schoolchildren

According to the data obtained, the share of EG learners with high results of the formation of the ability to speak was $35 \%$; with medium results - 46\%; with low results $19 \%$.

The formation of the ability to speak in CG is a little bit lower. The high level was demonstrated by $29 \%$ of learners, the medium and low levels - by $34 \%$ and $27 \%$ respectively. This indicates an improvement in the quality of the formation of the foreign language speaking among all learners, although the percentage of increase is not as high as in listening.

\section{Conclusion}

Thus, the developed author's CIK contribute to the development of the foreign language speech activity of the primary school learners, and also motivate learners to study $\mathrm{FL}$, as evidenced by the comments of school teachers. The analysis of the results of the diagnostic study allows us to conclude that the data of the expert evaluation of the CIK by the teachers of the schools testify to the effectiveness of its practical application. The carried out research also testifies to the validity of the diagnosis of the assessment of the educational results of the junior school children achieved in the process and result of learning English in the primary foreign-language education.

The obtained data on the formation in junior schoolchildren of the skills of foreign language listening and speaking in accordance with the program requirements testify in aggregate to the increase in the qualitative indicators of the development of the foreign speech ability in all the subjects and the positive dynamics of the formation of their foreign language speech activity by using author's teaching aids as additional resources that expand the possibilities of the educational process of teaching the foreign language.

\section{References}

Albert, I. P. (1999). Web-based Simulation Generator: Empowering Teaching and Learning Media in Political Science. Paper presented at ASCILTIE99.

Basal, Celen, Kaya \&Boğaz, (2016). An Investigation into Illustrations in English Course Books in a Turkish Context. International Electronic Journal of Elementary Education, 8(3), 525-536.

Basal, A. (2013). ELT teachers as online material developers. The Online Journal of Distance Education and e-Learning, 1(2), 8-12.

Brown, J. S., Collins, A., \& Duguid, P. (1989). Situated cognition and the culture of learning. Educational Researcher, 18(1), 32-42.

Bullard, N. (1990). Briefing and debriefing. In D. Crookall\& R. Oxford (Eds.), Simulation, gaming and language learning (pp. 55-67). New York: Newbury House.

Çakır, I. (2015). Instructional Materials Commonly Employed by Foreign Language Teachers at Elementary Schools. International Electronic Journal of Elementary Education, 8(1), 69-82.

Crookall, D., \& Oxford, R. (1990). Simulation, Gaming, and Language Learning. New York: Newbury House Publishers.

Crookall, D., Coote, A., Dumas, D., \& Le Gat, A. (1987). The ISAGA GAME: Inquisitive speaking and gameful acquaintance: $A$ mix of tongues and communicating across cultures. In D. Crookall, C. S. Greenblatt, A. Coote, J. Klabbers\& D. Watson (Eds.), Simulationgaming in the late 1980s (pp. 57-63). Oxford: Pergamon.

Davis, R. S. (1996). Simulations: A Tool for Testing "Virtual Reality" in the Language Classroom. In JALT '95: Curriculum and Evaluation. Tokyo: Japan Association for Language Teaching 
deHaan J. (2011). Teaching and learning English through digital game projects. Digital Culture \& Education, 3(1), 46-55.

deHaan J., Reed W. M., Kuwada K. (2010). The effect of interactivity with a music video game on second language vocabulary recall. Language Learning \& Technology, 14(2), 74-94.

Domin, E. A. (2007). On application of visuals in teaching English: Selected Issues. Retrieved from http://mail.publikacje.edu.pl/pdf/8385.pdf

Freiermuth, M. (2002). Connecting with computer science students by building bridges. Situation and Gaming, 3(3), 299-315.

Hewings, M. (1991). The interpretation of illustrations in ELT materials. ELT Journal, 45(3), 237-244. http://dx.doi.org/10.1093/elt/45.3.237

Javid, C. (2013). An investigation of effectiveness of simulation in developing oral skills: A case study. European Scientific Journal, 9(32), 254-270.

Jones, G. (1986). Computer simulations in language teaching -- the kingdom experiment. System, 14(2), $171-178$.

Kuzu, A., Akbulut, Y., \&Sahin, M. C. (2007). Application of Multimedia Design Principles to Visuals Used in Course-Books: An Evaluation Tool. The Turkish Online Journal of Educational Technology - TOJET, 6(2), 8-14.

Laitinen, M. (2014). Thousands of words. A comparative study on the functions of pictorial illustrations in English language textbooks. (Unpublished master's thesis). Retrieved

from https://jyx.jyu.fi/dspace/handle/123456789/43121

Meihami, H., Meihami, B., \&Varmaghani, Z. (2013). CALL in the form of simulation games: Teaching English vocabulary and pronunciation through sims. International Letters of Social and Humanistic Sciences, 8, 57-65.

Miller, M., \&Hegelheimer, V. (2006). The SIMS meet ESL: Incorporating authentic computer simulation games into the language classroom. International Journal of Interactive Technology and Smart Education, 3(4), 311328.
Molitor, S., Ballstaedt, S. P., \& Mandl, H. (1989). Problems in Knowledge Acquisition from text and Pictures. In Mandl, H. \& Levin, J. R. (Eds). Knowledge Acquisition from text and Pictures, 3-35. North Holland: Amsterdam, New York, Tokyo. http://dx.doi.org/10.1016/S0166-4115(08)62145-7

Nemitcheva, N. (1995). The Psychologist and Games in the Intensive Foreign Language Game-based Course. In D. Crookall\& K. Arai (Eds.), Simulation and Gaming across Disciplines and Cultures (pp. 70-74). Thousand Oaks, CA: Sage Publications.

Purushotma, R. (2005). Commentary: You're not studying, you're just . Language Learning \& Technology, 9(1), 8096.

Ranalli, J. (2008). Learning English with the sims: Exploiting authentic computer simulation games for 12 learning. Computer Assisted Language Learning, 21(5), 441-455.

Sam, Y. W. (1990). Drama in Teaching English as a Second Language - A Communicative Approach. In: The English Teacher (XIX); MELTA.

Schwienhorst, K. (2002). Why virtual, why environments? Implementing virtual reality concepts in computerassisted language learning. Simulation \& Gaming, 33(2), 196-209.

Teele, S. (1995). The multiple intelligences school: A place for all students to succeed. Redlands, CA: Citrograph.

Tompkins, K. P. (1998). Role Playing/Simulation. The Internet TESL Journal, 4(8).

Wang, Y. H. (2010). Using communicative language games in teaching and learning English in Taiwanese primary schools. Journal of Engineering Technology and Education, 7(1), 126-142.

Zhetpisbayeva, B. A., Shelestova, T. Y. \&Abildina S.K. (2016). Examining teachers' views on the implementation of English as L3 into primary schools: A case of Kazakhstan. International Electronic Journal of Elementary Education, 8(4), 659-674. 